\title{
A FLIPPED CLASSROOM TO ENHANCE STUDENTS' SELF-DIRECTION IN INFORMATICS AND PHYSICS ENGINEERING
}

\author{
Dina Adinda \\ University of Strasbourg, France \\ E-mail: adinda@etu.unistra.fr
}

\begin{abstract}
As one of the blended learning forms, a flipped classroom has its specific typology to differentiate itself from other blended learning models. Aims to support student-centered learning activities in which self-direction in learning might be fostered, the effect of flipped classroom scenario to students' self-direction had never been reviewed. This work, performed at the University of Strasbourg, involved lecturers who teach informatics and physics engineering course. First, observations of the online learning environments and face-to-face classes had been managed. Second, a pre and post-test questionnaire, which aimed to measure its participants' progress on self-direction, had been fulfilled by the students. This study pointed out that students enrolled in a translated flipped classroom course had not developed their self-direction competence. However, the significant progress of students' self-direction in learning has been documented among students enrolled in a course with an interactive flipped classroom scenario.
\end{abstract}

Keywords: blended learning setting, flipped classroom, self-direction, teaching approaches

\section{INTRODUCTION}

Blended learning is a formal education model in which students learn through the online and face-to-face session (Horn \& Stakers, 2015). This description suits to francophone researchers' definition of formation hybride (Peraya et al., 2014) which also points out the possibility for students to have their control over time, place and/or learning path. Indeed, to design a blended learning course, especially for the online sessions of the course, teachers need to pay attention to students' access to knowledge, which is embedded in the online platform. On this subject, Marquet (2017) stated that it is essential to correctly associate the three different types of artifact: didactical, pedagogical and technical, in the VLE (Virtual Learning Environments). Scientific works have recorded some positive impacts of blended learning on students' engagement (Peraya et al., 2014) and their satisfactory learning outcomes (Kintu et al., 2017). Nurmayani et al. (2017) highlighted that the latter-mentioned impact could be confirmed if the teachers provide interactive learning experiences and implement student-centered learning scenario so that students are encouraged to be an active learner and to develop their responsibility in learning.

As a dynamic rotation of blended learning (Lim \& Wang, 2016), the knowledge transmission in a flipped classroom scenario is performed notably in a constructivist or socioconstructivist approach (Lebrun \& Lecoq, 2015). Lim et al. (2016) argued that flipped classroom intends to shift the information diffusion approach to student-centered teaching approaches which can help students achieve deeper learning and understanding the course contents. Scientifics have also agreed that when students are involved in their learning and invited to be critical, they move from a surface to a deep learning process (Trigwell, et al., 2005; Hiemstra, 2015). Therefore, the online sessions of flipped classroom are intended to knowledge appropriation, and the face-to-face meetings are frequently dedicated to discussions, debates, problem-solving or presentation about a subject previously learned in the online platform. In this context, students' motivation to learn before attending face-toface sessions are fostered and the adoption of student-centered approaches to teach, which can 
actively promote the student-centered approach to learn (Gibbs \& Coffey, 2004), are also encouraged.

Everyday lives in the current digital era become more challenging. Unlimited information and new technologies have transformed the transmission of knowledge and communication. To meet the needs of the market and the society, behaviors that favor lifelong learning and competencies related to self-direction become essential. Carré et al. (2010) stated that self-direction is composed of the capacity of oneself to determinate his objective and to regulate his strategies in order to achieve the goal set, this precise definition distinguishes self-direction from autonomy. Through Carré's (2003) perspective about personal agency in social cognitive theory, selfdirection can be perceived as a behavior resulted by an active interaction between personal characteristics or experiences of an individual and his environment. Therefore, if teachers want his students to develop their selfdirection, and to become more self-directed in learning, it is preferable that the designed environment takes into account students' personal characteristics and their experiences in learning. Carré et al. (2011) completed this list with a useful technical aspect to foster students' self-direction: an online learning platform which offers students a possibility to learn in their own learning pace.

Taking into account various possible students' activities in learning and the objective of flipped classroom scenario, Lebrun \& Lecoq (2015) classified flipped classroom in three levels. Level 1 is a translated classroom. In this level, the flipped classroom implements a traditional learning scenario. However, the course contents are transferred to the online pedagogical platform. The students' online activities at this level are reading or watching video-based lectures. In face-to-face learning sessions, lecturer focuses on exercises and discussions or debates. The translated classroom scenario aims to develop metacognitive competence and encourage students to practice their comprehension, memory, and synthesis. When a debate is organized in the face-to-face session, then students' critical thinking is also targeted.

Level 2 is an interactive classroom. The students' learning activities at this level have only a few differences from the translated flipped classroom. However, the online and face-to-face activities at this level are more interactive and require students' active participation. They are also invited to work with their peers. Moreover, the designed learning environment for this level is more open; for instance, students can do or are encouraged to do documentary or literature research and to use external resources that they might find on the internet. In this type of flipped classrooms, students have to read or watch video-based lectures before attending the course. However, they also have some online exercises for the face-to-face meetings. Possible students' activities in face-to-face sessions are debates, analysis or peer review activities. Through these activities, students' analysis, communicational and teamwork skills are expected.

Level 3 is a combined classroom. The scenario of this flipped classroom mixes the activities and skills targeted in the translated and interactive flipped classrooms. This combination takes the form of a cycle divided into three objectives: contextualization, decontextualization, and recontextualization. Figure 1 shows a flipped classroom's scenario of this level adapted from Lebrun \& Lecoq (2015).

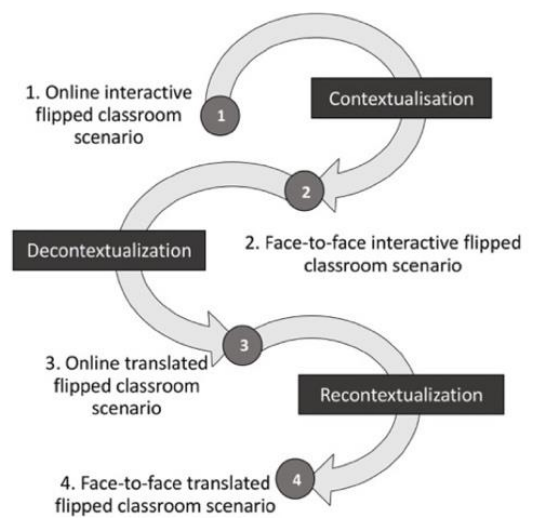

Figure 1. Combined Flipped Classroom Scenario 
These three levels of the flipped classroom were created by taking into account the skills that students experienced and practiced. Indeed, it is possible that each operation could have a different impact on students. Research conducted by Trigwell et al., (1999) has shown that course contents provided, teaching approaches and activities prepared by lecturers can influence students' interactivities and their learning approaches. Moreover, those aspects support the development of students' reflective skills (Lim \& Wang, 2016), which can foster their possibility to achieve a high level of selfdirection in learning.

Scientific works had well documented the effect of blended learning on students' outcomes, their engagement and their selfdirection in learning. However, the effect of the flipped classroom scenario, which is known as a dynamic blended learning form, to students' self-direction had never been reviewed. Demonstrating some possible flipped classroom scenarios in informatics and physics engineering courses, this study aimed to attest the impact of each flipped classroom level to students' self-direction, along with the aspects caused this effect. To achieve this goal, this work focuses on the analysis of flipped classroom's technical dimension and knowledge mediation which are directly related to students' activities. The second objective of this study focuses on enriching the actual knowledge about the flipped classroom by identifying the potential element to enhance students' self-direction in learning.

Since the combined flipped classroom implies a very complex scenario, the adoption of this level is quite rare. The first hypothesis of this study is that students, both in translated and interactive flipped classroom scenarios develop their self-direction in learning. Indeed, it is assumed that $p$-value of the students in two questioned flipped classroom levels is less or equal to the significance level. The second hypothesis is that individual or group exercise is the potential factor that influences the impact of a flipped classroom to students' selfdirection.

Performed at the University of Strasbourg, this work involves two lecturers who teach in informatics and physics engineering. Solicited students were enrolled in the last year of undergraduate studies. Students' level of study was chosen related to the actual problem of undergraduate failures in French universities. Since self-direction in learning is one of essential aspects to succeed university studies (Coulon, 2005), and to meet the needs of society as well as the labor market, this study also contributes to documenting students' selfdirection level in their last year of undergraduate studies. In the following sections, the results and the method that has been set up, which is based mainly on observations and questionnaire, will be detailed.

\section{METHOD}

The objectives of this study were to investigate the impact of each flipped classroom level (FCL) to students' self-direction in learning (SDL) and to identify the potential element in this dynamic blended learning form which can foster students' self-direction. The study was conducted at the University of Strasbourg from September 2017 to December 2017. Two courses were studied: informatics course (MIUDS) and physics engineering course (EAUDS). Two groups of respondents were selected: (1) Lecturers who teach informatics and physics engineering in undergraduate studies, and (2) undergraduate students enrolled in their courses. It covered 70 students and two lecturers.

This work adopted a mixed research approach and the method used to collect the data was the observations and the survey. First, observations of the online learning environments and face-to-face classes had been managed. Second, a pre and post-test questionnaire, which aimed to measure its participants' progress on self-direction, had been completed by students. 
In general, the objective of observations was to identify the types of the flipped classroom designed. Observation to the online platform aimed, more specifically, to determine the learning tools and the type of contents provided. It was also aimed to identify students' online learning activities. However, the face-toface observations were managed to identify activities organized in face-to-face meetings.

To discover the effect of identified FCL, students have been asked to answer a French version of Self-Directed Learning Readiness Scale (SDLRS) (Guglielmino, 1977) at the beginning and the end of the semester. To identify progression or regression of students' self-direction, a paired samples T-Test had been applied to the results of each survey.

The analysis of the collected data was directed along four principal axes: (1) level of the flipped classroom designed, (2) students' self-directed learning readiness scores, (3) tools and resources provided and (4) students' learning activities in online and face-to-face sessions. The method of this study is summarized in Table 1.

Table 1. Research Methods and Analysis Framework

\begin{tabular}{lll}
\hline \multicolumn{1}{c}{ Research objectives } & \multicolumn{1}{c}{ Axes of collected data } & \multicolumn{1}{c}{ Instruments } \\
\hline Investigate the impact of & Flipped classroom levels (FCL) & Observation guide \\
various FCL to SDL & Students SDLRS results & SDLRS \\
$\begin{array}{l}\text { Determine the potential } \\
\text { elements that foster SDL }\end{array}$ & $\begin{array}{l}\text { Tools and resources provided online and face-to- } \\
\text { face }\end{array}$ & Observation guide \\
& Students activities online and face-to-face & \\
\hline
\end{tabular}

The hypothesis of this study is as follow: (1) $\mathrm{H}_{1}$ : The p-value of students in the two types of flipped classrooms studied is less than the significance level. This indicates that students developed their self-direction in learning. (2) $\mathrm{H}_{2}$ : Individual or group exercise is the potential factor that influences students' self-direction.
Table 2 presents the observation guide used to determine the type of FCL, tools used, students' activities, and contents provided. Meanwhile, to measure students' self-direction in learning, the survey guideline adapted from Guglielmino (1977) is presented in Table 3.

Table 2. Observation Guide and Its Indicators

\begin{tabular}{|c|c|c|}
\hline Variable & Sub Variables & Indicators \\
\hline \multirow[t]{2}{*}{$\begin{array}{l}\text { Flipped } \\
\text { classroom } \\
\text { levels }\end{array}$} & $\begin{array}{l}\text { Translated flipped } \\
\text { classroom (L1) }\end{array}$ & $\begin{array}{l}\text { Online discussion forum (FR), textual (TC) and multimedia course } \\
\text { contents (MC), external resources or sites (ER) } \\
\text { Students' online learning activities: reading the course contents (RC), } \\
\text { watching video-based lectures (WV). } \\
\text { Face-to-face learning activities: discussion (DS), case study (CS), debate } \\
\text { (DB) }\end{array}$ \\
\hline & $\begin{array}{l}\text { Interactive flipped } \\
\text { classroom (L2) }\end{array}$ & $\begin{array}{l}\text { Online discussion forum (FR), textual (TC) and multimedia course } \\
\text { contents (MC), external resources or sites (ER) } \\
\text { Students' online learning activities: reading the course contents (RC), } \\
\text { watching video-based lectures (WV), individual practice (IP), group } \\
\text { activities or exercises (GA), literature or documentary research (DR) } \\
\text { Face-to-face learning activities: discussion (DS), case study (CS), debate } \\
\text { (DB), analysis or peer review activities (PR). }\end{array}$ \\
\hline
\end{tabular}

Combined flipped Online tools required in level 1 and 2 are used

classroom (L3) The scenario mixes the activities and skills targeted in the translated and interactive flipped classroom. It takes form of a cycle divided into three objectives: contextualization, decontextualization, and recontextualization 
Table 3. Survey Guideline for Students' Self-Direction in Learning (SDLRS)

\begin{tabular}{|c|c|c|c|}
\hline Variable & Sub Variables & Indicators & Question Items \\
\hline \multirow{8}{*}{$\begin{array}{l}\text { Participants' } \\
\text { self-directed learning } \\
\text { readiness }\end{array}$} & \multirow[t]{2}{*}{ Self-determination } & - Initiative and independence in learning & $\begin{array}{c}2,6,7,18,27,42 \\
55,58\end{array}$ \\
\hline & & $\begin{array}{l}\text { - Acceptance of his own responsibility in } \\
\text { learning }\end{array}$ & $\begin{array}{c}8,13,15,20,21 \\
40,50\end{array}$ \\
\hline & \multirow[t]{3}{*}{ Self-regulation } & - Openness to learning opportunities & $3,22,34,35,39$ \\
\hline & & - Creativity & $25,29,36,48$ \\
\hline & & $\begin{array}{l}\text { - Ability to use study and problem- } \\
\text { solving skills }\end{array}$ & $4,10,12,51$ \\
\hline & \multirow[t]{3}{*}{ Self-efficacy } & - Self-concept as an effective learner & $\begin{array}{c}9,11,16,33,38 \\
41,44,57\end{array}$ \\
\hline & & - Passion to learn & $\begin{array}{c}5,14,19,23,24, \\
28,30,32,43,45, \\
47,53\end{array}$ \\
\hline & & - Orientation to the future & $\begin{array}{l}1,17,26,31,37 \\
46,49,52,54,56\end{array}$ \\
\hline
\end{tabular}

\section{RESULTS AND DISCUSSION}

The observation had well-documented students' learning activities and tools as well as the resources provided in online and face-toface sessions. Table 4 shows the information collected through observation that helped to identify the type of flipped classrooms. It also shows some differences in terms of tools as well as students' activities in the two modules studied. From the perspectives of tools and resources, the physics engineering course
(EAUDS) provided multimedia course content. Scientific works have shown that video-based lectures can provide alternative interpretations and introduce different perspective of the studied subject (The national academies, 2000). Compared to textual resources, this type of support improves more students' attention to the topic as well as their concentration levels (Nikopoulou-Smyrni \& Nikopoulos, 2010).

Table 4. Observation results

\begin{tabular}{|c|c|c|c|c|c|c|c|c|c|c|c|c|c|}
\hline \multirow[b]{2}{*}{ Course studied } & \multicolumn{4}{|c|}{$\begin{array}{c}\text { Tools and resources } \\
\text { provided }\end{array}$} & \multicolumn{4}{|c|}{ Face-to-face activities } & \multicolumn{5}{|c|}{ Online activities } \\
\hline & FR & $\mathrm{TC}$ & $\mathrm{MC}$ & ER & DS & CS & DB & PR & WV & $\mathrm{RC}$ & GA & IP & DR \\
\hline EAUDS & $\checkmark$ & $\checkmark$ & $\checkmark$ & No & $\checkmark$ & $\checkmark$ & No & $\checkmark$ & $\checkmark$ & $\checkmark$ & No & $\checkmark$ & No \\
\hline MIUDS & $\checkmark$ & $\checkmark$ & No & $\checkmark$ & $\checkmark$ & No & No & No & No & $\checkmark$ & No & No & No \\
\hline
\end{tabular}

(FR: Forum, TC: Textual course, MC: Multimedia course content, ER: External resources, DS: Discussions, CS: Case study, DB: Debate, PR: Peer review, WV: Watching video-based lectures, RC: Reading course contents, GA: Group activities or exercises, IP: Individual exercise, DR: Documentary research)

Referring to the Table 4, the lecturer of the informatics course (MIUDS) used only textual resources. However, an external source was provided: in the online platform, the lecturer put a hyperlink of a scientific journal in which students can read papers related to the course content. This action might be a sign that MIUDS' lecturer gave his students some possibilities to find their own references to get a better understanding of the course contents.

Regarding students' learning activities, the observation results shows that EAUDS 
engaged students in some interactive and collaborative works: students had some exercises and group activities in which they were invited to evaluate, analyze and give some suggestions to improve work of their peers. However, students of MIUDS have only experienced teacher-centered lectures while learning in the face-to-face session. Prosser et al. (2005) affirmed that discussion is one of the activities introduced through a teacher-centered approach to teach. In this activity, students are more passives than they who experienced a student-centered teaching approach (debates or peer-review activities) because the teacher can be the one who starts the discussion and have a directive role in it. Indeed, through the list of tools and resources provided, as well as students' learning activities presented in Table 4, EAUDS can be classified as an interactive flipped classroom whereas the informatics course (MIUDS) is categorized as a translated flipped classroom scenario.

A learning environment is one of the determinants of TRC (Triadic Reciprocal Causation) (Bandura, 1997). Vaughan et al. (2013) stated that a blended learning environment is composed of various elements including instructional design, tools, resources, facilitation or mentoring provided, and the learning scenario implemented. In the perspective of TRC, those elements are and were influenced by other determinants in the triangle; students' behavior in learning and their personal characteristics (Ponton \& Carr, 2012). Indeed, a particular impact of a specific learning environment to students' behavior in learning can be introduced by a different implementation of one of its constitutive elements. This study has identified two different types of flipped classroom scenarios. Since the objective of a flipped classroom is to help students achieve deeper learning (Lim \& Wang, 2016), it is possible to assume that this type of blended learning scenario favors students' positive learning outcomes and the development of their competencies, including their self-direction in learning. However, taking into account students' activities and interactivity of each learning scenario, the level of competencies developed could be different from one type to another. This perspective is resumed in the first hypothesis of this study. To investigate this hypothesis a Self-Directed Learning Readiness Scale (SDLRS) was used. This scale was constructed by Guglielmino (1977) to measure individuals' self-direction levels.

The Pearson split-half test estimated that reliability of the original survey $(\mathrm{N}=3151)$ was 0.94 (Guglielmino, 1989). Since a French translation of SDLRS was used in this context, the reliability of each item was re-estimated using Cronbach's coefficient alpha. It is regarded that a value of coefficient alpha above 0.8 suggests a good degree of homogeneity, and a value above 0.5 shows an acceptable degree of homogeneity (Hinton et al., 2004).

Table 5 shows that all of the 58 items, for which coefficient alpha was computed, achieved a good degree of reliability $(\mathrm{N}=200)$. A Pearson correlation test was also managed to analyze the validity of questionnaire items. The obtained correlation is used to measure the validity of an item and to determine whether an item can be used or not. Table 5 shows the correlation of the 58 items in 8 indicators of SDLRS. The p-value obtained shows that correlation of 57 items is significant at the .01 level.

The statistical test in Table 5 indicates that p-value of Q19 is more than .10. It means that this item is not valid and cannot be used. As a consequence, the French version of SDLRS used in this study only consists of 57 questions. However, it might be caused by a misinterpretation of the item by respondents. Indeed, the item could be rephrased in a way in which students could better see their own learning experience. So that, their understanding of the item might be improved. 
Table 5. Reliability and Validity of French

\begin{tabular}{cccc}
\multicolumn{4}{c}{ Version's SDLRS } \\
\cline { 1 - 3 } Item & Cronbach's & $\begin{array}{c}\text { Pearson } \\
\text { correlation } \mathrm{r}\end{array}$ & p-value \\
& $\alpha$ & Item total & \\
\cline { 1 - 2 } Indicator: & Initiative and independence in learning \\
Q2 & 0.873 & 0.427 & $<0.001$ \\
Q6 & 0.874 & 0.400 & $<0.001$ \\
Q7 & 0.872 & 0.441 & $<0.001$ \\
Q18 & 0.872 & 0.508 & $<0.001$ \\
Q27 & 0.870 & 0.598 & $<0.001$ \\
Q42 & 0.871 & 0.547 & $<0.001$ \\
Q55 & 0.871 & 0.504 & $<0.001$ \\
Q58 & 0.874 & 0.470 & $<0.001$
\end{tabular}

\begin{tabular}{|c|c|c|c|}
\hline \multicolumn{4}{|c|}{ Indicator: Acceptance of his own responsibility } \\
\hline Q8 & 0.876 & 0.306 & $<0.001$ \\
\hline Q13 & 0.873 & 0.369 & $<0.001$ \\
\hline Q15 & 0.876 & 0.521 & $<0.001$ \\
\hline Q20 & 0.875 & 0.458 & $<0.001$ \\
\hline Q21 & 0.872 & 0.408 & $<0.001$ \\
\hline Q40 & 0.871 & 0.500 & $<0.001$ \\
\hline Q50 & 0.875 & 0.499 & $<0.001$ \\
\hline \multicolumn{4}{|c|}{ Indicator: Openness to learning opportunities } \\
\hline Q3 & 0.872 & 0.638 & $<0.001$ \\
\hline Q22 & 0.873 & 0.536 & $<0.001$ \\
\hline Q34 & 0.871 & 0.504 & $<0.001$ \\
\hline Q35 & 0.872 & 0.663 & $<0.001$ \\
\hline Q39 & 0.871 & 0.446 & $<0.001$ \\
\hline \multicolumn{4}{|c|}{ Indicator: Creativity } \\
\hline Q25 & 0.873 & 0.493 & $<0.001$ \\
\hline Q29 & 0.874 & 0.687 & $<0.001$ \\
\hline Q36 & 0.872 & 0.575 & $<0.001$ \\
\hline Q48 & 0.872 & 0.554 & $<0.001$ \\
\hline
\end{tabular}

\begin{tabular}{cccr}
\hline \multicolumn{4}{c}{ Indicator: Ability to study and problem solving } \\
Q4 & 0.873 & 0.510 & $<0.001$ \\
Q10 & 0.872 & 0.678 & $<0.001$ \\
Q12 & 0.872 & 0.682 & $<0.001$ \\
Q51 & 0.871 & 0.517 & $<0.001$
\end{tabular}

Indicator: Self-concept as an effective learner

$\begin{array}{cccc}\text { Q9 } & 0.872 & 0.394 & <0.001 \\ \text { Q11 } & 0.872 & 0.640 & <0.001 \\ \text { Q16 } & 0.874 & 0.372 & <0.001 \\ \text { Q33 } & 0.873 & 0.531 & <0.001 \\ \text { Q38 } & 0.871 & 0.659 & <0.001 \\ \text { Q41 } & 0.872 & 0.617 & <0.001 \\ \text { Q44 } & 0.871 & 0.446 & <0.001 \\ \text { Q57 } & 0.874 & 0.458 & <0.001\end{array}$

\begin{tabular}{|c|c|c|c|}
\hline \multicolumn{4}{|c|}{ Indicator: Passion to learn } \\
\hline Q5 & 0.870 & 0.572 & $<0.001$ \\
\hline Q14 & 0.872 & 0.388 & $<0.001$ \\
\hline Q19 & 0.875 & 0.024 & 0.732 \\
\hline Q23 & 0.872 & 0.424 & $<0.001$ \\
\hline Q24 & 0.873 & 0.375 & $<0.001$ \\
\hline Q28 & 0.870 & 0.605 & $<0.001$ \\
\hline Q30 & 0.871 & 0.616 & $<0.001$ \\
\hline Q32 & 0.871 & 0.496 & $<0.001$ \\
\hline Q43 & 0.870 & 0.524 & $<0.001$ \\
\hline Q45 & 0.869 & 0.678 & $<0.001$ \\
\hline Q47 & 0.870 & 0.648 & $<0.001$ \\
\hline Q53 & 0.870 & 0.546 & $<0.001$ \\
\hline \multicolumn{4}{|c|}{ Indicator: Orientation to the future } \\
\hline Q1 & 0.871 & 0.602 & $<0.001$ \\
\hline Q17 & 0.872 & 0.587 & $<0.001$ \\
\hline Q26 & 0.870 & 0.451 & $<0.001$ \\
\hline Q31 & 0.875 & 0.339 & $<0.001$ \\
\hline Q37 & 0.874 & 0.420 & $<0.001$ \\
\hline Q46 & 0.870 & 0.616 & $<0.001$ \\
\hline Q49 & 0.871 & 0.616 & $<0.001$ \\
\hline Q52 & 0.871 & 0.558 & $<0.001$ \\
\hline Q54 & 0.871 & 0.570 & $<0.001$ \\
\hline Q56 & 0.873 & 0.286 & $<0.001$ \\
\hline
\end{tabular}

Table 6 below presents the mean score of pre and post-test results.

Table 6. Students' Pre-test and Post-test Mean Scores

\begin{tabular}{lccc}
\hline Course & $\begin{array}{c}\text { Pre-test } \\
\text { Mean }\end{array}$ & $\begin{array}{c}\text { Post-test } \\
\text { Mean }\end{array}$ & $\begin{array}{c}\text { Mean } \\
\text { Difference }\end{array}$ \\
\hline EAUDS & 204.1 & 213.4 & -9.25 \\
MIUDS & 207.9 & 207.7 & 0.129 \\
\hline
\end{tabular}

Table 6 points out that the mean scores of EAUDS' students have 9.25 difference. The pre-test of MIUDS showed 0.12 point higher than the post-test. It indicated a possible regression of MIUDS' students. To confirm that those differences were significant, a paired samples T-Test was managed. The results were presented in Table 7.

Table 7. Paired Samples T-Test Results

\begin{tabular}{ccc}
\hline Course & $\mathrm{t}$ & $\mathrm{p}$-value \\
\hline EAUDS & -1.785 & 0.059 \\
MIUDS & 0.077 & 0.530 \\
\hline
\end{tabular}


Figure 2 shows the descriptive plots of EAUDS' paired samples T-Test results and the Figure 3 presented the plots of MIUDS' results.

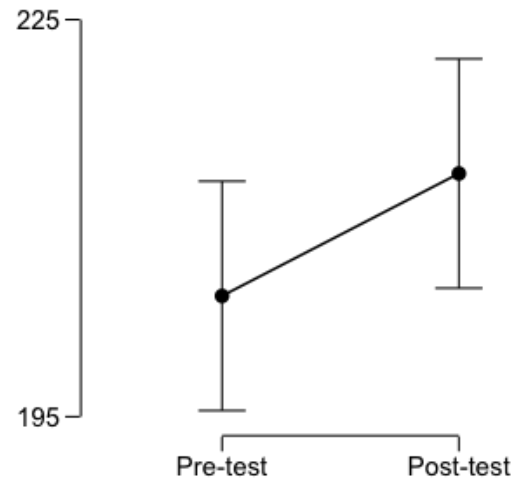

Figure 2. Descriptive Plots of EAUDS' Paired Samples T-Test Results

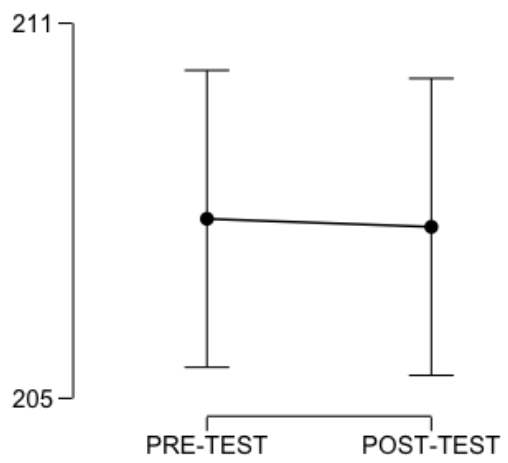

Figure 3. Descriptive Plots of MIUDS’ Paired Samples T-Test Results

The statistical test presented in Table 7 indicates that the p-value of EAUDS' students is less than .10. This showed that students had developed their self-direction score. Otherwise, the p-value of MIUDS' students is more than .10 which indicates that there is no significant difference between the result of pre and posttests. Indeed, this result shows that the translated flipped classroom has no impact on students' self-direction. However, the significant progress of students' self-direction in learning have been documented among students enrolled in a course with an interactive flipped classroom scenario.

The statistical test has shown that $\mathrm{H}_{1}$ was rejected. As the two types of flipped classroom studied required different resources, tools and learning' scenarios, it is obvious that students' activities are also different from one type to another. (1) In the term of tools used to transfer knowledge, several differences between the two course modules studied were acknowledged. Some different impacts of this element to students' knowledge acquisition were also affirmed by Nikopoulou-Smyrni \& Nikopoulos (2010). (2) Regarding the differences in term of teaching strategies implemented, Berthiaume \& Justeau (2015) also affirmed that studentcentered teaching approaches enhance more students' deep and active learning.

In this study, an interactive and collaborative work, which represent active learning, are identified in the interactive flipped classroom scenario (EAUDS). Moreover, EAUDS used a multimedia content, while the observation results indicated that MIUDS provided textual contents, teacher-centered teaching approach, less interactive activities and did not encourage collaborative work. Those elements explain why students in a translated flipped classroom (MIUDS) cannot meet the expected level of the p-value.

The observation results confirmed that, Unlike EAUDS, MIUDS did not provide individual exercises for students in its online session. Furthermore, students' of EAUDS develop their self-direction in learning. Indeed, this result can confirm the $\mathrm{H}_{2}$ of this work, but to investigate, in detail, what is exactly the potential factor that influences students' selfdirection, research with more respondents shall be conducted.

\section{CONCLUSION}

Despite its limitations, this work revealed that in flipped classroom contexts, a proper combination of technical aspects and studentcentered instructional design is essential to foster students' self-direction. From the technical point of view, it appears that the choice of resources and tools used in flipped classroom scenario could determine students' learning activities and the development of their personal competencies. This study indicated 
that students who enrolled in a course module with multimedia contents develop their selfdirection level. This fact has also been presented by Lam (2014) who stated that multimedia tools and digital technologies are essentials to helps students to have higher consciousness and understanding of their objectives and strategies in learning.

From the pedagogical point of view, this study pointed out that an interactive learning scenario is necessary. The t-test's result has shown that a flipped classroom scenario, in which students develop their self-direction in learning, had an interactive scenario: students were invited to work in a group or individually, and their critical thinking, as well as conceptual change, were encouraged.

Indeed, the results of this study validated Lebrun \& Lecoq's (2015) statement which confirmed that each level of flipped classrooms introduces to different impact on students' learning activities. Furthermore, when it comes to students' self-direction in learning, this study reveals that certain conditions have to be completed. (1) Multimedia contents need to be used and (2) Teaching scenario must favor active and interactive learning. Indeed, it confirms that each level of flipped classroom scenarios also has a different impact on the development of students' self-direction in learning.

\section{REFERENCES}

Bandura, A. 1997. Self-efficacy: The Exercise of Control. New York: Freeman

Berthiaume, D. \& Justeau, S. 2015. Recourir au mentorat pour développer son expertise en enseignement, In Berthiaume, D., Rege-Colet, N. (Eds). La pédagogie de l'enseignement supérieur: repères théoriques et applications pratiques. Berne. Peter Lang, 169-183

Carré, P., Moisan, A., \& Poisson, D. 2010. L'autoformation, Perspectives de Recherche. Paris: Press Universitaire de France
Carré, P. 2003. La double dimension de l'apprentissage autodirigé Contribution à une théorie du sujet social apprenant. Canadian Journal for the Study of Adult Education. 17, 66-91

Carré, P., Jézégou, A., Kaplan, J., Cyrot, P. \& Denoyel, N. 2011. L'Autoformation: The State of Research on Self-Directed Learning in France. International Journal of Self-Directed Learning. 8, 7-17

Coulon, A. 2005. Le métier d'étudiant, l'entrée dans la vie universitaire. Paris: Economica

Gibbs, G. \& Coffey, M. 2004. The Impact of Training of University Teachers on their Teaching Skills, their Approach to Teaching and the Approach to Learning of their Students. Active Learning in Higher Education. 5, 87-100

Guglielmino, L. 1989. Reaction to Field's investigation into the SDLRS. Adult Education Quarterly. 39, 235-245

Guglielmino, L. 1977. Development of the SelfDirected Learning Readiness Scale. Dissertation. United States: University of Georgia

Hiemstra, R. 2015. Faciliter L'apprentissage Autodirigé des Adultes. Savoirs. 1.37, 53-73

Hinton, P.R., Brownlow, C., McMurray, I., \& Cozens, B. 2004. SPSS Explained. London: Routledge

Horn, M.B., Staker, H. 2015. Blended: Using Disruptive Innovation to Improve Schools. San Francisco, CA, USA: JoseyBass

Kintu, M.J., Zhu, C., \& Kagambe, E. 2017. Blended learning effectiveness: the Relationship between Student Characteristics, Design Features, and Outcomes. International Journal of Educational Technology in Higher Education. 14. 7 
Lam, J. 2014. The context of blended learning: The TIPS blended learning model. International Conference on Hybrid Learning and Continuing Education (ICHL). Shanghai. 80-92

Lebrun, M. \& Lecoq, J. 2015. Classes Inversées enseigner et apprendre à l'endroit! France: Réseau Canopé

Lim, C., Cho, Y.H., \& Kim, S. 2016. Partnerships and Innovation for Blended Learning at Seoul National University, Republic of Korea. Blended Learning for Quality Higher Education: Selected Case Studies on Implementation from AsiaPacific. Lim, C.P \& Wang, L. Editors. Bangkok: Unesco Bangkok Office, 211232

Lim, C.P. \& Wang, T. 2016. A Framework and Self-Assessment Tool for Building the Capacity of Higher Education Institutions for Blended Learning. Blended Learning for Quality Higher Education: Selected Case Studies on Implementation from Asia-Pacific. Lim, C.P \& Wang, L. Editors. Bangkok: Unesco Bangkok Office, $1-38$

Marquet, P. 2017. Digital Media Research in Education: The Usefulness of the Instrumental Conflicts Theory. Jurnal Pendidikan Teknologi dan Kejuruan. 23. 4, 311-327

Nikopoulou-Smyrni, P., Nikopoulos, C. 2010. Evaluating The Impact of Video-Based Versus Traditional Lectures on Student Learning. Educational Research. 1.8, 304-311

Nurmayani, S., Sugiarti, Y., \& Mujdalipah, S. 2017. Application of Blended Learning Model in Agricultural Vocational High
Schools. Jurnal Pendidikan Teknologi dan Kejuruan. 23. 4, 355-361

Peraya, D., Charlier, B., \& Deschryver, N. 2014. Une première approche de l'hybridation. Education et Formation. e301, 15-34

Prosser, M., Martin, E., Trigwell, K., Ramsden, P., \& Lueckenhausen, G. 2005. Academics' Experiences of Understanding of Their Subject Matter and the Relationship of This to Their Experiences of Teaching and Learning. Instructional Science. 33. 2, 137-157

Ponton, M.K. \& Carr, C. 2012. Autonomous learning and triadic reciprocal causation: a theoretical discussion. International Journal of Self-Directed Learning. 9. 1, $1-10$

The National Academies. 2000. How People Learn: Brain, Mind, Experience, and School: Expanded Edition. Washington, D.C.: National Academies Press

Trigwell, K., Prosser, M., \& Ginns, P. 2005. Phenomenographic pedagogy and a Revised Approaches to Teaching Inventory. Higher Education Research \& Development. 24, 349-360

Trigwell, K., Prosser, M., \& Waterhouse, F. 1999. Relations between Teachers' Approaches to Teaching and Students' Approaches to Learning. Higher Education, 37. 1. 57-70

Vaughan, N.D., Cleveland-Innes, M., Garrison, D.R., 2013. Teaching in Blended Learning Environments: Creating and Sustaining Communities of Inquiry. Edmonton: AU Press 